\title{
Intravitreal silicone injection in retinal detachment
}

\author{
J. J. KANSKI AND R. DANIEL \\ Retina Unit, Moorfields Eye Hospital, High Holborn Branch, London
}

The use of intravitreal liquid silicone injection into the human eye was first reported by Cibis, Becker, Okun, and Canaan (1962). Until then, the prognosis of retinal detachment complicated by massive vitreous retraction (MVR) was considered to be hopeless.

This form of treatment was first used in this hospital in 1964. Its use was considered only when it became apparent that conventional re-attachment procedures had failed or had no chance of success. This paper reports the results obtained with liquid silicone alone or in conjunction with a scleral buckling procedure in 36 such cases. Liquid silicone combats MVR by freeing adhesions between vitreous membranes and the retina, and by tamponading the retina against the choroid.

\section{Patients and method}

Table I shows that, of 36 eyes treated with liquid silicone, 26 had massive vitreous retraction; amongst these were included three giant tears. Ten patients had either total or partial detachments without MVR. One of these had a giant tear extending $180^{\circ}$, with a fixed rolled posterior edge, and another was a diabetic traction detachment with no visible breaks.

All but one of the 36 cases had already had from one to four unsuccessful retinal procedures. Twelve eyes ( 33 per cent.) were aphakic. In sixteen patients the fellow eye had no useful vision. The average age was $46 \cdot 7$ years (range 12 to 69 ), and 64 per cent. of the patients were males. In all, 39 operations using silicone were carried out as three patients had two injections each.

The technique used was essentially the same as described by Cibis and others (1962) and Okun and Arribas (1969). As much as possible of the subretinal fluid was drained and silicóne was injected through a meridional sclerotomy in the pars plana, 5 to $6 \mathrm{~mm}$. behind the limbus. Under indirect ophthalmoscopic control, the needle was guided into the depths of the retinal funnel to lie as near to the disc as possible. The amount of silicone injected varied from $\mathrm{I}$ to $4 \mathrm{ml}$., except in one highly myopic eye in which a total of $6.5 \mathrm{ml}$. was injected by two separate procedures.

\section{Results}

At the time of writing ten patients have been observed for less than 6 months, thirteen from 6 months to 2 years, and thirteen from 2 to 8 years.

Of the 36 eyes treated with intravitreal silicone, an anatomical improvement was achieved in eighteen (50 per cent.) (Table II). In six cases the retina was completely re-attached posterior to the ridge; the visual acuity was improved in four, unchanged in one, and decreased in one. The remaining twelve cases were judged to have been only partially successful as there was still residual detachment present, usually involving the lower part of the fundus. Of these cases, four had improved visual acuity, in four the visual acuity was unchanged, and in four it was decreased. The functional results are 
shown in Table III. Two cases deserve special mention (Cases 2 and I I-see Table IV), as the improvement in vision was exceptionally good. In Case 2 the vision was improved from perception of light to $5 / 60$. The improvement lasted for a year but the acuity then fell to hand movements. In Case i I the vision improved from counting fingers to 6/24, but this lasted for only 3 months and then fell to hand movements. In the former case the reduction in vision was due to progression of lens opacities; the exact cause of subsequent visual deterioration in the latter is difficult to ascertain.

Table III Functional

Table I Types of cases treated

\begin{tabular}{|c|c|c|c|c|c|}
\hline Type & Number & Type & Number & Type & Number \\
\hline $\begin{array}{l}\text { MVR (including three giant tears) } \\
\text { Retinal detachments without MVR }\end{array}$ & $\begin{array}{l}26 \\
\text { 10 }\end{array}$ & $\begin{array}{l}\text { Retina completely flat } \\
\text { Retina partially flat } \\
\text { No change }\end{array}$ & $\begin{array}{r}6 \\
12 \\
18\end{array}$ & $\begin{array}{l}\text { Vision improved } \\
\text { No change } \\
\text { Worse }\end{array}$ & $\begin{array}{r}8 \\
11 \\
17\end{array}$ \\
\hline Total & 36 & Total & 36 & Total & $3^{6}$ \\
\hline
\end{tabular}

Table IV Details of anatomically improved cases

\begin{tabular}{|c|c|c|c|c|c|c|c|}
\hline \multirow[b]{2}{*}{ Retina } & \multirow{2}{*}{$\begin{array}{l}\text { Case } \\
\text { No. }\end{array}$} & \multirow[b]{2}{*}{ Preoperative retina } & \multirow{2}{*}{$\begin{array}{l}\text { Duration of } \\
\text { follow-up }\end{array}$} & \multicolumn{3}{|c|}{ Visual acuity } & \multirow[b]{2}{*}{ Comments } \\
\hline & & & & Pre-op & $\begin{array}{l}\text { Best } \\
\text { post-op }\end{array}$ & Final & \\
\hline \multirow[t]{6}{*}{$\begin{array}{l}\text { (a) Com- } \\
\text { pletely flat }\end{array}$} & $\mathbf{I}$ & Partial RD & 3 yrs & GF & PL & No PL & $\begin{array}{l}\text { Silicone in anterior } \\
\text { chamber } \\
\text { Cataract } \\
\text { Glaucoma }\end{array}$ \\
\hline & 2 & Partial RD & 2 yrs & PL & $5 / 60$ & HM & $\begin{array}{l}\text { Posterior lens } \\
\text { opacities }\end{array}$ \\
\hline & 3 & MVR & $\mathrm{I} \cdot 5 \mathrm{yrs}$ & HM & HM & HM & \\
\hline & 4 & Total RD & $\mathrm{I} \mathrm{yr}$ & HM & CF & GF & $\begin{array}{l}\text { Early posterior lens } \\
\text { opacities }\end{array}$ \\
\hline & 5 & MVR & $2 \mathrm{mths}$ & PL & HM & HM & \\
\hline & 6 & $\begin{array}{l}\text { Subtotal RD } \\
\text { Aphakia }\end{array}$ & I mth & HM & GF & GF & \\
\hline \multirow[t]{12}{*}{$\begin{array}{l}\text { (b) Partially } \\
\text { flat }\end{array}$} & 7 & MVR & $4 \mathrm{yrs}$ & $\mathrm{HM}$ & $\mathrm{HM}$ & HM & $\begin{array}{l}\text { Early posterior lens } \\
\text { opacities }\end{array}$ \\
\hline & 8 & MVR Aphakia & $3 \mathrm{yrs}$ & PL & HM & HM & \\
\hline & 9 & Partial RD & 2 yrs & $4 / 60$ & GF & HM & \\
\hline & 10 & $\begin{array}{l}\text { Partial RD } \\
\text { Aphakia }\end{array}$ & $2 \mathrm{yrs}$ & $6 / 36$ & CF & CF & $\begin{array}{l}\text { Silicone in anterior } \\
\text { chamber }\end{array}$ \\
\hline & I I & MVR & 2 yrs & CF & $6 / 24$ & HM & \\
\hline & 12 & Total RD & 2 yrs & HM & CF & GF & $\begin{array}{l}\text { Posterior lens } \\
\text { opacities }\end{array}$ \\
\hline & 13 & $\begin{array}{l}\text { Total RD } \\
\text { Aphakia }\end{array}$ & $\mathrm{I} \cdot 5 \mathrm{yrs}$ & HM & HM & HM & \\
\hline & 14 & $\begin{array}{l}\text { Total RD } \\
\text { Giant tear }\end{array}$ & $1 \cdot 5$ yrs & HM & HM & PL & \\
\hline & 15 & MVR Aphakia & $6 \mathrm{mths}$ & HM & GF & CF & \\
\hline & I6 & MVR Aphakia & $6 \mathrm{mths}$ & PL & HM & HM & \\
\hline & I 7 & MVR Aphakia & 4 mths & HM & HM & HM & \\
\hline & 18 & MVR Giant tear & I mth & HM & HM & HM & \\
\hline
\end{tabular}


In the majority of cases showing functional improvement it was found that the improvement was only from perception of light to hand movements or from hand movements to counting fingers. Of the four cases with giant tears treated, two were anatomically but not functionally improved. Of the twelve aphakic eyes, seven were anatomically improved and did not show a higher incidence of complications than phakic eyes. This finding is contrary to other reports which stress that aphakic eyes have a much worse prognosis than phakic eyes.

It must be stressed that anatomical improvement does not necessarily imply functional improvement.

Of the eighteen cases which were not improved anatomically, six retained their preoperative visual acuity and twelve had diminished acuity after the operation. It is very important to mention this possibility to the patient, before embarking on surgery.

It is interesting to note that, of seven patients who have been followed up from 3 to 8 years, five have no perception of light and two only hand movements. So far, the best functional long-term results have been those in Cases 10 and 12 , who have retained a visual acuity of counting fingers (walking vision) for 2 years since the operation.

\section{Complications}

On the whole, the short-term ocular tolerance to silicone is very good. The complications were divided into those occurring during the surgical procedure and those occurring later.

The most serious operative complication was vitreous haemorrhage, which was probably caused by trauma to the retina or choroid by the tip of the needle.

Of the late complications, lens opacities occurred in eight (33 per cent.) of the phakic patients; four were of the posterior subcapsular or posterior cortical type, one was nuclear, and three advanced nuclear and cortical (one of these was mature). As it is known that eyes with long-standing retinal detachments frequently develop complicated cataracts, one cannot implicate the presence of silicone oil as the aetiological factor in all of these cases.

Corneal dystrophy was a very late complication, occurring after several years in three patients, two of whom were aphakic. It was not associated with the pressure of silicone in the anterior chamber.

Silicone entered the anterior chamber in two aphakic patients, but at the time of writing has not caused any complications. In one phakic patient, a small bubble of silicone had passed around the lens into the anterior chamber.

Secondary glaucoma occurred in two patients, but was easily controlled medically. In each case the eye was blind.

Several patients developed a mild anterior uveitis, but only in two cases did it lead to the formation of posterior synechiae.

\section{Comment}

Owing to the very poor functional results obtained, intravitreal injection of liquid silicone should be reserved for patients with only one potentially useful eye, which has an otherwise hopeless prognosis and no chance of cure by any other procedure.

Damage to the retinal cells by contact with silicone, and the many late complications observed, as well as the initial "inoperable" state of the eye, were all contributory factors to the poor functional results. 


\section{Summary}

Liquid silicone was used to treat $3^{6}$ cases of retinal detachment. $5^{\circ}$ per cent. of the eyes were anatomically improved, but the improvement in visual function was disappointing, there being only a marginal improvement in 22 per cent.

We are grateful to Mr. J. R. Hudson for allowing us to report on the cases under his care.

\section{References}

CiBis, P., BeCKer, B., okUn, E., and canaAn, s. (1962) Arch. Ophthal. (Chicago), 68, 590

oKUn, E., and ARribas, N. P. (1969) In "Symposium on Retina and Retinal Surgery", chapter I8, pp. 278-293. Mosby, St. Louis 